\title{
Kyphomelic dysplasia: the first 10 cases
}

\author{
Peter D Turnpenny, Riad A Dakwar, Farid N Boulos
}

\begin{abstract}
We report two sibs, the ninth and tenth cases of a distinctive familial skeletal dysplasia. Designated kyphomelic dysplasia, the condition is a short limbed dwarfism characterised by very short angulated femora, variable bowing of other long bones, irregular, flared metaphyses, restricted joint mobility, a small thorax and short trunk, a normal cranium and psychomotor development, and a tendency for the bowing to improve with age in survivors. The first born of our cases died of pneumonia at $2 \frac{1}{2} 2$ months of age and is known to us by radiographs only. The second case was under our care from birth. He died aged 13 months after developing a pure red cell aplasia in the second half of infancy, which spontaneously recovered about the time of onset of his final illness. These cases are discussed in relation to previous reports.
\end{abstract}

In 1983 Maclean et al ${ }^{1}$ summarised their own case, together with four other reported cases, ${ }^{23}$ of a distinctive skeletal dysplasia whose main feature was very short, angulated femora. The first two cases reported by Khajavi et $a l^{2}$ were described as a normocephalic, short limbed variety of the campomelic syndrome, but the condition is distinct and Maclean et $a^{1}$ proposed the nomenclature kyphomelic dysplasia.

Since the report of Maclean $e a^{1}$ there have been three further cases published. ${ }^{45}$ From those eight cases there were two pairs of affected sibs and only one known affected female (the sex of the two cases in the first report ${ }^{2}$ is not documented). Inheritance is therefore assumed to be autosomal recessive. Short,

Paediatric Department, The Nazareth Hospital, EMMS, PO Box 11, 16100 Nazareth, Israel.

$P$ D Turnpenny

Orthopaedic Department, The Nazareth Hospital, Israel. R A Dakwar

Department of Radiology, The Nazareth Hospital, Israel.

F N Boulos

Correspondence to Dr Turnpenny.

Received for publication 15 June 1989.

Revised version accepted for publication 17 August 1989. angulated femora, rhizomelic-mesomelic limb shortening with variable bowing of the long bones, irregular, flared metaphyses, restricted joint mobility, narrow thorax, short trunk, normal occipitofrontal circumference (OFC) and psychomotor development, and a tendency for the limb bowing to improve with age in survivors are all consistent features. Variable features include micrognathia, midface hypoplasia, long philtrum, abnormal rib number and structure, platyspondyly, increased acetabular angles, and skin dimpling over bony prominences. Documentation, however, has not been complete in all cases.

The two sibs reported here show a remarkable consistency with the main features that have emerged from the other reported cases.

\section{Case reports}

CASE 1

The first affected child, a male, was born in 1982 to first cousin Arab parents who already had two normal children, a boy and a girl. He was delivered normally at 37 weeks' gestation, birth weight $2500 \mathrm{~g}$, OFC 35.0 $\mathrm{cm}$. At the age of $2 \frac{1}{2}$ months he was admitted to hospital with a chest infection and died one week later with pneumonia and disseminated intravascular coagulation. Admission weight was $3300 \mathrm{~g}$ ( $<3$ rd centile), OFC $38.0 \mathrm{~cm}$ (approximately 10th centile), length $40 \mathrm{~cm}(<<3$ rd centile). He was noted to have broad hands. A skeletal survey was performed and, when reviewed, the radiological features were found to be identical to those of case 2. Between the two affected children the mother had another normal daughter.

\section{CASE 2}

The second affected child, also male, was born in 1987 after an uneventful pregnancy without prenatal investigations; the mother was then 28 years old and the father 29 years. Delivery was by footling breech presentation at 38 weeks' gestation, birth weight 2660 g, OFC $35 \cdot 0 \mathrm{~cm}$. Short limbed dwarfism was immediately obvious, affecting the rhizomelic more than the mesomelic segments (fig 1). There was marked bilateral positional talipes equinovarus and skin dimples were present over the mildly bowed tibiae at the apex of the bowing (fig 2). The cranium was normal, but the face was mildly dysmorphic with 


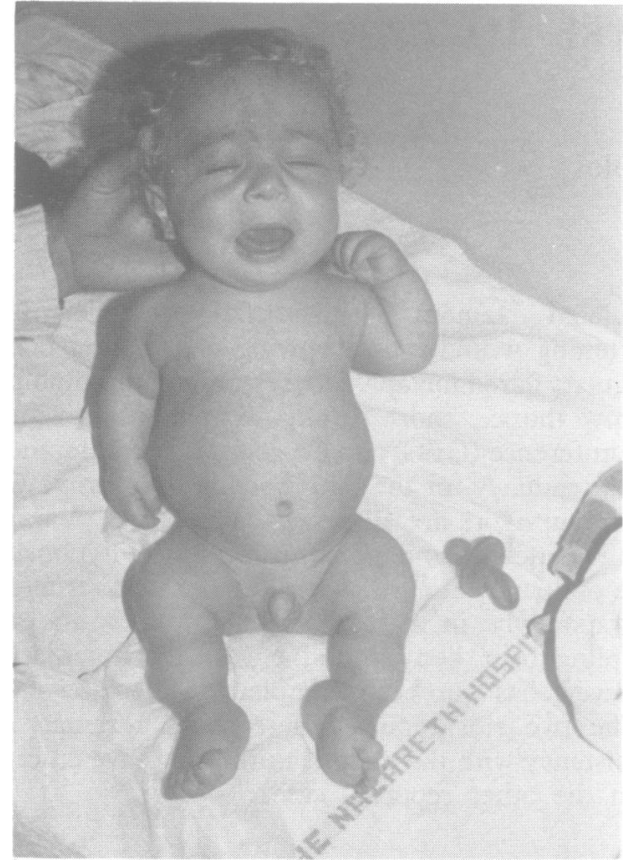

Figure 1 General appearance of case 2 (crying) at 8 months of age.

midface hypoplasia and a long philtrum. He was mildly hypotonic.

As the infant was followed, the talipes corrected well with splinting and the mild facial dysmorphism became less obvious. Mild hypotonia persisted and he did not thrive well, but psychomotor development was normal. His thorax was narrow, giving rise to moderately severe episodes of respiratory distress with upper respiratory infections, and as he grew it was clear that his hands and feet were broad. At 3 months his weight was $3300 \mathrm{~g}(<<3$ rd centile), length $43.5 \mathrm{~cm}$ ( $<<3$ rd centile), OFC $39.0 \mathrm{~cm}$ (10th to 25 th centile). For the next six months these growth parameters progressed parallel to the centile lines.

At 5 months of age his haemoglobin $(\mathrm{Hb})$ was $13 \cdot 3$ $\mathrm{g} / \mathrm{dl}$. Two months later he presented with anaemia with $\mathrm{Hb} 5 \cdot 2 \mathrm{~g} / \mathrm{dl}$. The reticulocyte count was zero and no normoblasts were seen in a bone marrow sample from the iliac crest. Megakaryocytes were present and granulopoiesis was normal. A diagnosis of pure red cell aplasia was made but he failed to respond to a two week course of prednisolone ( $30 \mathrm{mg} /$ day). He received five blood transfusions before erythropoiesis began spontaneously at 11 months. By this time he was losing weight and, despite supplemented feeding and parenteral nutrition, he did not improve. A repeat bone marrow aspiration 17 days before his death was normal and no malignant cells were seen. Blood urea nitrogen, serum electrolytes, serum calcium, phosphate, and alkaline phosphatase, blood gases, urine analysis, and serum protein electrophoresis were all normal. The stools showed no evidence of malabsorption and no parasites were seen on microscopy. Blood, urine, and stool cultures were consistently negative and apart from intercurrent infections he was afebrile. No necropsy was performed and the cause of death remains uncertain.

His maximum recorded naked weight was $5580 \mathrm{~g}$ at 10 months, which fell to $4400 \mathrm{~g}$ two months later. Measurements at $101 / 2$ months were OFC $44.3 \mathrm{~cm}$ (10th centile), crown-heel length $53.5 \mathrm{~cm}(<<3$ rd centile), crown-rump length $40 \mathrm{~cm}$ (approximately 10th centile), and chest circumference $37 \mathrm{~cm}$.

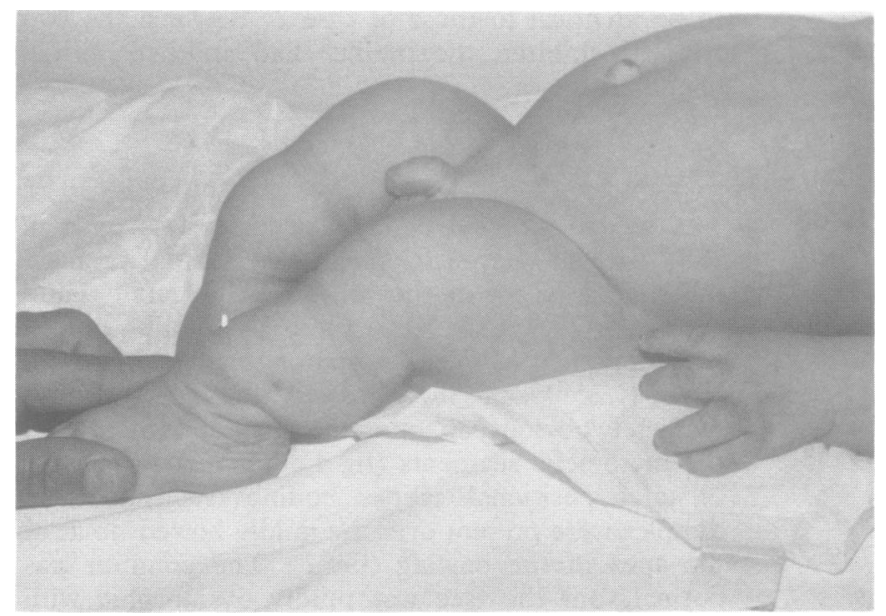

Figure 2 Left lateral view of case 2 at 8 months showing skin dimpling and a broad hand (thumb adducted out of sight). 

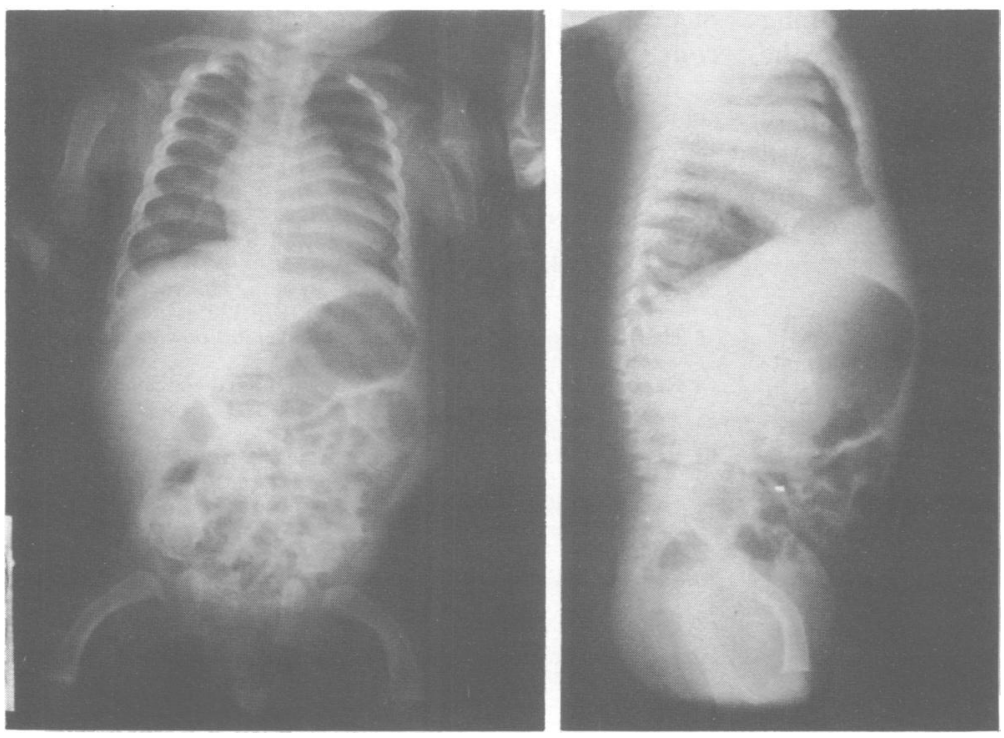

Figure 3 General skeletal appearances in case 2 at 7 months of age. (Left) anteroposterior view. (Right) Lateral view.
Femoral bowing was still marked at the age of 7 months (fig 3).

\section{Discussion}

These two cases are the third sib pair to be reported with this condition and are consistent in all the main features described so far. The features of case 2 are summarised in tables 1 to 3 . In previous cases the hands and feet were described as normal until the eighth reported case, where clinodactyly was present. ${ }^{5}$

Our case 2 is the first described to have been complicated by pure red cell aplasia. From the clinical course, the aetiology is likely to have been acquired

Table 1 Summary of phenotypic and radiological features found in the subjects of this report.

\begin{tabular}{lc}
\hline & $\begin{array}{c}\text { Manifest in } \\
\text { previously reported } \\
\text { cases (maximum } \\
\text { possible number 8) }\end{array}$ \\
\hline Rhizomelic-mesomelic limb shortening & 8 \\
Very short femora with marked bowing & 8 \\
Flared irregular metaphyses & 8 \\
Narrow thorax & 8 \\
Narrow shoulders & 6 \\
Short ribs & 6 \\
Flared rib ends & 6 \\
Normal cranium and OFC & 8 \\
Normal psychomotor development & 8 \\
Restricted joint (hip) mobility & 4 \\
Mid-face hypoplasia & 4 \\
Mild bowing of the radii & 7 \\
Mild bowing of the tibiae & 5 \\
Skin dimpling over bony prominences & 2 \\
(tibiae) & 1 \\
Long philtrum (early infancy only) & 0 \\
Broad tubular bones of the hands and feet & 0 \\
Mild hypotonia & \\
\hline
\end{tabular}

Table 2 Significant normal findings in the cases of this report (fig 3). ${ }^{6}$

\begin{tabular}{ll}
\hline & $\begin{array}{c}\text { Manifestation in previous } \\
\text { reported cases }\end{array}$ \\
\hline $\begin{array}{l}\text { Normal trunk length } \\
\text { No platyspondyly }\end{array}$ & $\begin{array}{l}\text { Short in } 5 \text { cases } \\
\text { Reported as present in 4, } \\
\text { possibly 5, cases } \\
\text { Increased angles in } 4 \\
\text { cases } \\
\text { Bowed in } 6 \text { cases }\end{array}$ \\
Straight humeri & acetabular angles
\end{tabular}

Table 3 Other reported findings not present in the cases of this report.

\begin{tabular}{lc}
\hline & No of cases \\
\hline 11 pairs of ribs & 2 \\
Chest deformity (pectus carinatum) & 3 \\
Hypoplastic ulnae & 2 \\
Hypoplastic fibulae & 1 \\
Clinodactyly & 1 \\
\hline
\end{tabular}

rather than resulting from congenital late onset Blackfan-Diamond syndrome. The course is consistent with a transient erythroblastopenia. ${ }^{7}$ The only drugs taken were promethazine and amoxycillin.

Both these cases died early, but in neither is it clear that early death was an inevitable consequence of the malformation syndrome. Case 1 suffered a similar fate to one of a sib pair previously reported, ${ }^{4}$ suggesting that a small thorax in these subjects is a significant risk factor in infancy.

Karyotyping was not done in our cases but was normal in two cases studied. ${ }^{14}$ 
There has been an attempt to discredit the grouping of all these reports into one condition, ${ }^{8}$ but so far the phenotypic and radiological features have stood the test of criticism ${ }^{9}$ and we can do no better until there are further clues to the aetiology of metaphyseal disorders. The term kyphomelic dysplasia has also been criticised as inappropriate, ${ }^{4}$ but no alternative has yet been proposed.

We thank Professor J Spranger, Mainz, Germany, for radiological interpretation; Dr E Stockdale, Department of Radiology, Royal Aberdeen Children's Hospital; Dr B Sharon, Department of Haematology, Rambam Medical Centre, Haifa, Israel; Department of Radiology, Afula Hospital, Israel; Dr P Bingham, Coventry; and Miss Jennifer Coward for secretarial assistance in preparing the manuscript.

Note added in proof

This paper was submitted just before the publication of an additional case of kyphomelic dysplasia (Temple et al. $\mathcal{F}$ Med Genet 1989;26:457-61).

1 Maclean RN, Prater WK, Lozzio CB. Skeletal dysplasia with short angulated femora (kyphomelic dysplasia). Am $\mathcal{f}$ Med Genet 1983;14:373-80.

2 Khajavi A, Lachman R, Rimoin D, et al. Heterogeneity in the campomelic syndromes. Radiology 1976;120:641-7.

3 Hall BD, Spranger JW. Familial congenital bowing with short bones. Radiology 1979;132:611-4.

4 Rezza E, Iannaccone G, Lendvai D. Familial congenital bowing with short thick bones and metaphyseal changes, a distinct entity. Pediatr Radiol 1984;14:323-7.

5 Vilioen D, Beighton P. Kyphomelic dysplasia: further delineation of the phenotype. Dysmorphol Clin Genet 1988;1:136-41.

6 Hensinger RN. Standards in pediatric orthopedics. New York: Raven Press, 1986:27, 36

7 Willoughby MLN. In: Forfar JO, Arneil GC, eds. Textbook of paediatrics. 3rd ed. Edinburgh: Churchill Livingstone, 1984: 943-5.

8 Pitt D. Kyphomelic dysplasia versus femoral hypoplasia-unusual facies syndrome. Am f Med Genet 1986;24:365-6.

9 Maclean RN. Reply to Dr Pitt. Am F Med Genet 1986;24:367-8. 